\title{
The Development of Finite Element Model to Investigate the Structural Performance of Reinforced Concrete Hollow Beams
}

\author{
Jen Hua Ling ${ }^{*}$, Lin Li Chan, Wen Kam Leong, How Teck Sia \\ School of Engineering and Technology, University College of Technology Sarawak, MALAYSIA \\ Jalan University, 96000, Sibu, Sarawak, Malaysia \\ *Corresponding authors: lingjenhua@ucts.edu.my
}

SUBMITTED 9 January 2020 REVISED 17 January 2020 ACCEPTED 4 March 2020

\begin{abstract}
The self-weight of a reinforced concrete beam contributes to the permanent loads of a structure. This can be reduced by creating a longitudinal void along the beam so that it will not affect the performance of the beam. In addition, this process can reduce the amount of building cost. Therefore, a finite element model was developed in this study with the aid of a computer program, Ansys, to investigate the behaviour of the hollow beam. The model was tested for reliability by comparing the predicted results with those obtained from the experiment in terms of the load-displacement responses, mechanical properties, and parametric responses. The result showed that the reliability of the model was questionable. The main cause of the non-reliability was the inaccurate prediction of the beam deflection by the model. The poor prediction of the beam deflection led to significant variations of relevant mechanical properties including stiffness, deflection, and ductility. For beam deflection, only $1 / 3$ of the specimens were correctly predicted with a reliability of $36 \%$ while the strength properties were discovered to have higher values as observed in the yield and the ultimate strengths with $73 \%$ and $64 \%$ respectively. However, both the model and experimental results showed the hollow beam was relatively effective when the diameter of the longitudinal void was $1 / 3$ times of the beam width and placed at the neutral axis. For the evaluation to improve the reliability, some revision including the properties of the materials, boundary conditions of the beam support, bonding conditions between different materials, and meshing shape and size suppose to be applied to the model.
\end{abstract}

KEYWORDS ANSYS Modelling; Beam Deflection; Circular Longitudinal Void; Finite Element Model; Reinforced Concrete Hollow Beam.

(c) The Author(s) 2020. This article is distributed under a Creative Commons Attribution-ShareAlike 4.0 International license.

\section{INTRODUCTION}

Reinforced concrete (RC) beam is used to sustain a building load but its weight also constitutes part of this load and, for it to be reduced, fewer reinforcements in longer span are required through the use of hollow beams. This process also leads to a reduction in building cost. A hollow beam has a longitudinal void along its span caused by the removal of concrete using lightweight void formers such as Polyvinyl Chloride (PVC) pipes (Joy and Rajeev, 2014; Varghese and Joy, 2016; Ragavi, 2017; Dhinesh and Satheesh, 2017; Al-Gasham, 2015; Ngu, 2017; Parthiban and Neelamegam, 2017), Polystyrene foams (Manikandan et al., 2015), Polypropylene plastic sheets (Kumbhar and Jadhav, 2018) and plastic bottles (Mathew and Varghese, 2016; Sariman and Nurdin, 2018). These beams have been reported to generally offer a lower strength compared to the solid ones (Kumbhar and Jadhav, 2018; Al-Gasham, 2015; Alshimmeri and AlMaliki, 2014; Alnuaimi et al., 2008; Inoue and Egawa, 1996). This was associated with the changes caused by the void in its cross-sectional configuration which reduces its second moment of inertia and affects its strength (Ngu, 2017). However, an effective design of hollow beam has the ability to offer a comparable or higher strength than solid ones (Varghese and Joy, 2016; Ragavi, 2017, Varghese and Joseph, 2016). This better performance is achieved with the 
placement of the void along the neutral axis of the beam (Mathew and Varghese, 2016).

The presence of the void near the soffit affects the flexural strength of the beam by degrading the bond performance of the tension bars (AlGasham, 2015). This further leads to the concentration of the stresses at the sharp corners of the void with a consequent effect on the beam's performance (Bhattarai and Bhattarai, 2017). Therefore, a circular longitudinal void is preferred in the design of an effective beam (Manikandan et al., 2015).

This study developed a finite element model with the aid of a computer program, Ansys, to investigate the behaviour of RC hollow beams. However, even if the model has the ability to predict the beam response, it is quite dangerous to design based on the simulated results. Therefore, the reliability of the model was determined using the experimental results provided by Ngu (2017).

\section{METHODS}

\subsection{Specimen Details}

A finite element model was developed to simulate a four-point load test conducted on 11 RC beam specimens including 2 solids and 9 hollows as shown in Figure 1 . The diameter, $d_{v}$, and position, $h_{v}$, of the void, as well as those of the point load, $a$, were varied as presented in Table 1 and Figure 2. The details of the beam are summarized as follows.

$\begin{array}{ll}\text { Dimension } & : 150 \mathrm{~mm} \times 300 \mathrm{~mm} \times 1650 \mathrm{~mm} \\ \text { Clear span, } l_{\text {eff }} & : 1500 \mathrm{~mm} \\ \text { Reinforcements } & : \text { Top bars, 2T10 }\left(f_{y k}=500 \mathrm{MPa}\right) \\ & : \text { Bottom bars, 2T12 }\left(f_{y k}=500\right. \\ & \mathrm{MPa}) \\ & : \text { Stirup, R8-150 (flexural } \\ & \text { test), R8-250 (shear test) }\left(f_{y k}=\right. \\ & 250 \mathrm{MPa}) \\ \text { Concrete cover } & : 25 \mathrm{~mm}(\text { all sides }) \\ \text { Void diameter, } d_{v} & : 25 \mathrm{~mm}, 50 \mathrm{~mm} \text { and } 75 \mathrm{~mm} \\ \text { Position of void } & : \text { Between } 39 \mathrm{~mm} \text { and } 139 \mathrm{~mm} \\ & \text { from beam soffit. }\end{array}$

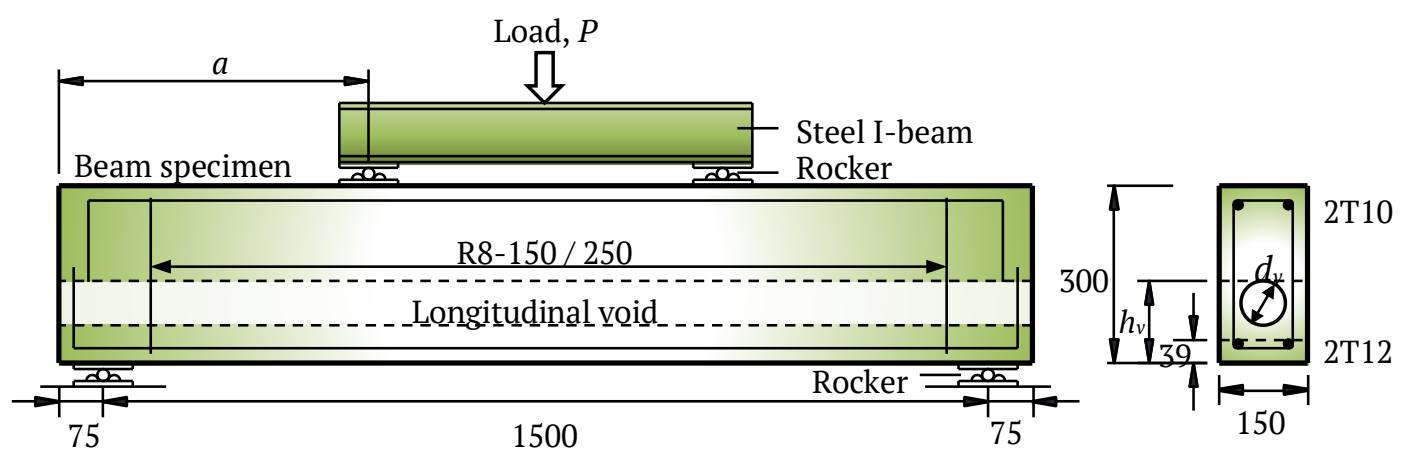

Figure 1. Test setup by Ngu (2017). (Dimensions in mm unless stated otherwise)

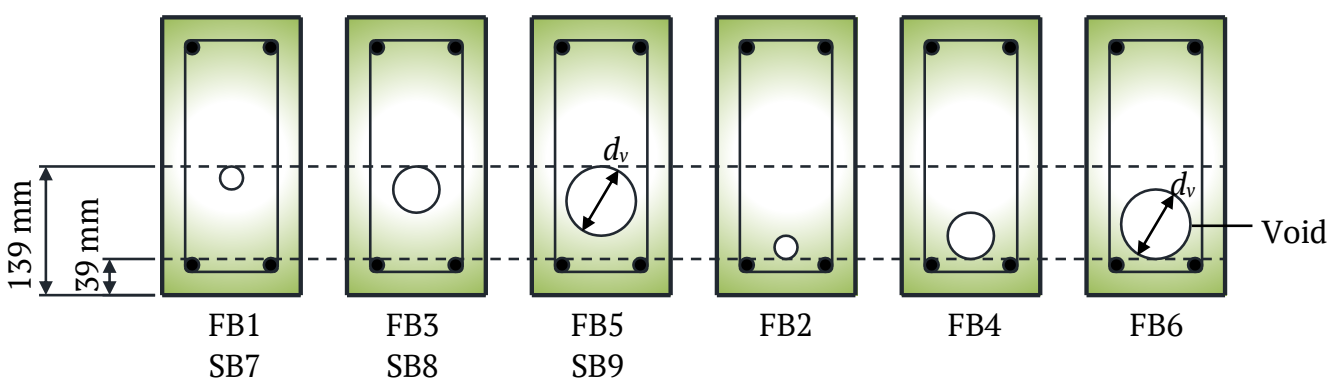

Figure 2. Position of the longitudinal void by specimens 
Table 1. Specimen details

\begin{tabular}{|c|c|c|c|c|c|}
\hline \multirow[b]{2}{*}{ Specimens } & \multicolumn{2}{|c|}{ Longitudinal void } & \multirow{2}{*}{$\begin{array}{c}\text { Point load } \\
\text { Distance from } \\
\text { support, } a(\mathrm{~mm})\end{array}$} & \multirow{2}{*}{$\begin{array}{c}\text { Shear } \\
\text { reinforcement }\end{array}$} & \multirow[b]{2}{*}{ Remarks } \\
\hline & $\begin{array}{c}\text { Position, } \\
h_{v}(\mathrm{~mm})\end{array}$ & $\begin{array}{c}\text { Diameter, } \\
d_{v}(\mathrm{~mm})\end{array}$ & & & \\
\hline CB1 & - & - & 600 & R8-150 & Control, Flexural \\
\hline CB2 & - & - & 500 & $\mathrm{R} 8-250$ & Control, Shear \\
\hline FB1 & 139 & 25 & 600 & $\mathrm{R} 8-150$ & Flexural test \\
\hline FB3 & 139 & 50 & 600 & $\mathrm{R} 8-150$ & Flexural test \\
\hline FB5 & 139 & 75 & 600 & $\mathrm{R} 8-150$ & Flexural test \\
\hline FB2 & 64 & 25 & 600 & $\mathrm{R} 8-150$ & Flexural test \\
\hline FB4 & 89 & 50 & 600 & $\mathrm{R} 8-150$ & Flexural test \\
\hline FB6 & 114 & 75 & 600 & $\mathrm{R} 8-150$ & Flexural test \\
\hline SB7 & 139 & 25 & 500 & $\mathrm{R} 8-250$ & Shear test \\
\hline SB8 & 139 & 50 & 500 & $\mathrm{R} 8-250$ & Shear test \\
\hline SB9 & 139 & 75 & 500 & $\mathrm{R} 8-250$ & Shear test \\
\hline
\end{tabular}

\subsection{Finite Element Model}

In Ansys, the concrete beam, longitudinal void, and steel reinforcements were modelled using rectangle, cylinder, and line geometries, respectively. The reinforcement was assumed to be linearly bonded with the concrete with vertical uniform loads applied on top of the beam as shown in Figure 3. Moreover, roller support was used with zero displacements in the $y$ - and $z$ directions and free movement in the $x$-direction.

The properties of the material used in the model are listed in Table 2 and, for simplicity, the Polyvinyl Chloride (PVC) pipe used by Ngu (2017) to create the longitudinal void in the beam was ignored, assuming (a) it contributed no strength to the beam, and (b) the existence of a poor bond between the pipe and the concrete. The tetrahedron meshing was used as shown in Figure 4 , with the sizes provided in Table 3 determined after several trials until the predicted results (a) reached constant values, and (b) became close to the experimental results.

As shown in Figure 3, the uniform distributed load was acted on the beam and increased progressively. Then, the computed beam deformation was recorded after which the loaddisplacement $(P-\delta)$ curve was plotted in realtime. However, the beam was considered to have failed when (a) a sudden drop in the $P$ - $\delta$ curve, (b) an illogical shape in the beam, or (c) an unrealistically large beam deflection $\left(\delta \geq 0.01 l_{\text {eff }}\right)$ was observed.

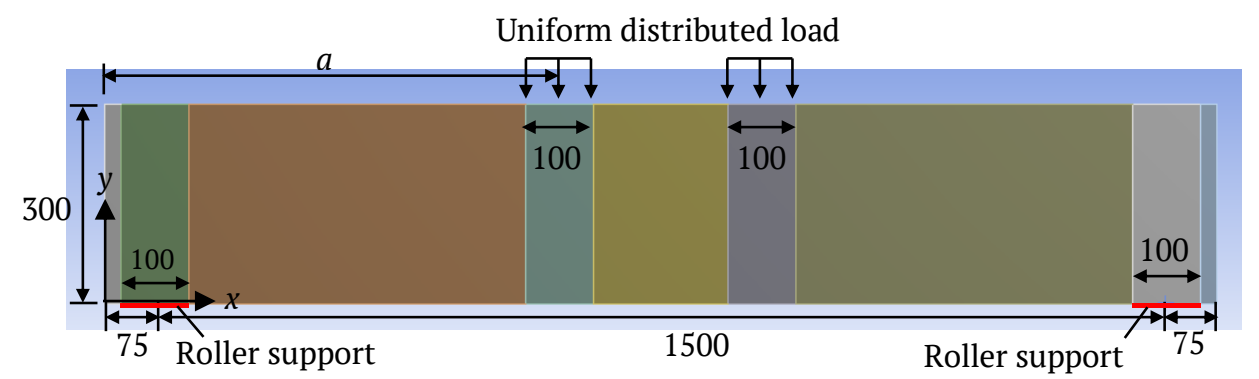

Figure 3. Simulated beam setup (Dimensions in $\mathrm{mm}$ unless stated otherwise) 

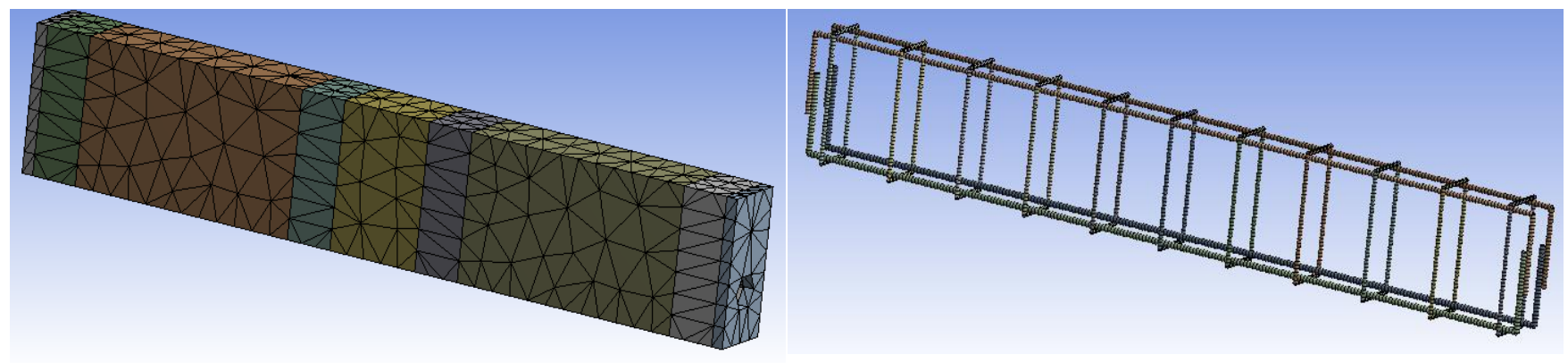

(a) Concrete beam

(b) Reinforcement

Figure 4. Simulated beam setup (Dimensions in $\mathrm{mm}$ unless stated otherwise)

Table 2. Material properties of the model

\begin{tabular}{llll}
\hline Materials & Concrete & Rebar & Stirrup \\
\hline Element & Solid65 & Link180 & Link180 \\
Young modulus, $E(\mathrm{MPa})$ & 24,000 & 200,000 & 200,000 \\
Poisson ratio & 0.2 & 0.3 & 0.3 \\
Density, $\rho\left(\mathrm{kg} / \mathrm{m}^{3}\right)$ & 2400 & 7850 & 7850 \\
Specified tensile yield strength, $f_{\text {yk }}(\mathrm{MPa})$ & - & 500 & 250 \\
Compressive strength, $f_{c k}(\mathrm{MPa})$ & 25 & - & - \\
\hline
\end{tabular}

Table 3. Mesh Size of the modelled beam ( $\mathrm{mm}$ )

\begin{tabular}{lll}
\hline Specimen & Concrete & Reinforcements \\
\hline CB1 & 60 & 2 \\
CB2 & 37 & 2 \\
FB1 & 38 & 2 \\
FB2 & 48 & 7 \\
FB3 & 53 & 3 \\
FB4 & 38 & 3 \\
FB5 & 45 & 7 \\
FB6 & 46 & 4 \\
SB7 & 46 & 3 \\
SB8 & 47 & 4 \\
SB9 & 37 & 7 \\
\hline
\end{tabular}

\section{RESULTS AND DISCUSSION}

The simulated response of the beam was compared with the experimental results in terms of (a) load-displacement responses, mechanical properties, and (c) parametric responses.

\subsection{Load-Displacement Response}

The modelled and the experimental loaddisplacement responses were compared by overlaying the $P-\delta$ curves one over another and respectively denoted as FEM for simulation response and EXP for the experimental result, as shown in Figure 5.

The predicted responses were found to be similar to the experimental results in the following aspects:

a. The $P-\delta$ curves were somewhat close to each other as observed from the appearance of identical parabolic curves with the experimental results by most of the specimens. 
b. The beam stiffness, represented by the tangential gradient of the curve, gradually decreased as the load increased.

c. The beam deflection was also discovered to increase with the load.

However, the following variations were observed:

a. The modelled response had an initial load resistance, approximately $10 \mathrm{kN}$, with respect to a negligible deflection when it was first applied to the beam but this was not exhibited in the experiment. This could be due to the assumption of an ideal linear bond between the tension bars and the concrete in the model. However, in reality, for the micro-gaps between the bar ribs and the concrete, the bond consolidated as the beam was first loaded. Therefore, the deflection developed in the experiment was without an initial load resistance.

b. The model generally predicted a higher degree of beam stiffness, particularly when (i)

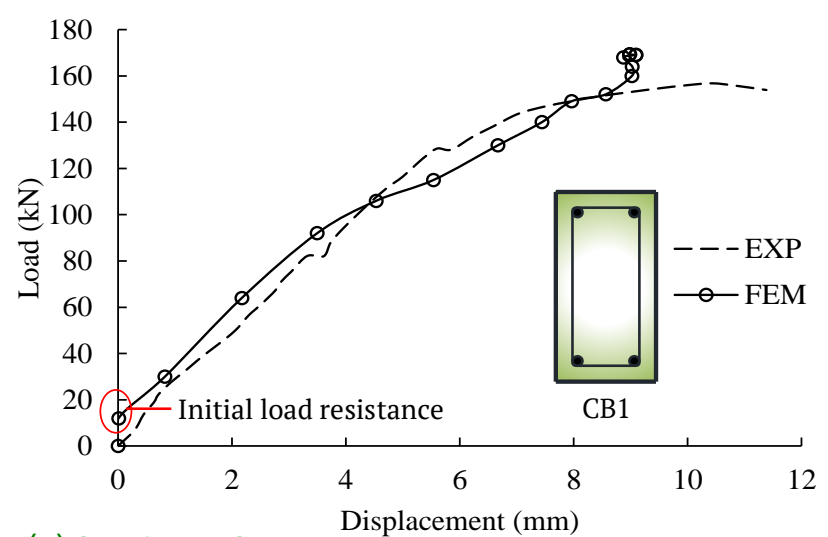

(a) Specimen CB1

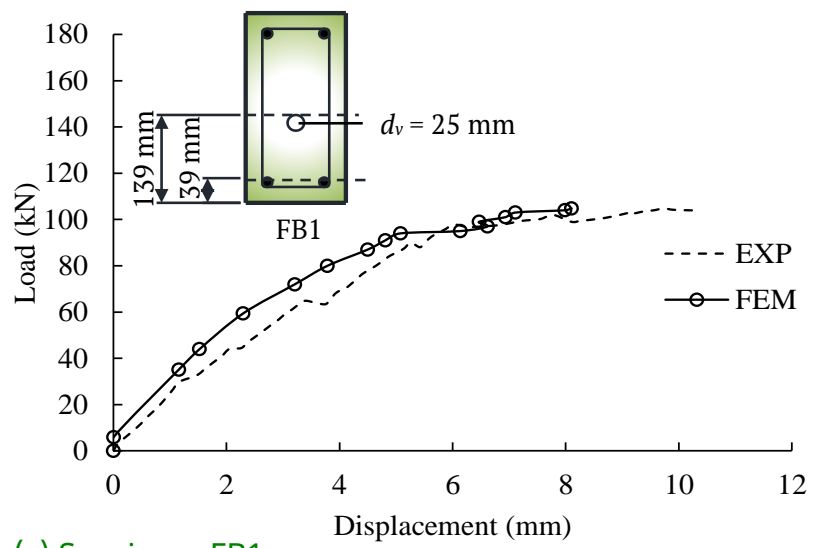

(c) Specimen FB1 the hollow beams were subjected to shear load, or (ii) when the void size, $d_{v}$, was small at $25 \mathrm{~mm}$. However, this variation reduced (i) at the later stage of loading, and (ii) when the void size was increased. Moreover, for the linear bonding, stresses in the beam were assumed to have been effectively transferred between concrete and tension bars. In reality, the beam cracked and the stresses were fully resisted by the tension steel bars to produce a larger deflection and lower stiffness as observed in the experiment.

c. For the same reason, the model generally predicted a smaller ultimate deflection in the beam in comparison to the experiment.

d. The model sometimes overestimated the beam capacity, particularly when (i) the void was placed close to the soffit, or (ii) the beam was subjected to a shear load. This normally happened when the void size was larger than $1 / 3$ of the beam's width $\left(d_{v} \geqslant 50 \mathrm{~mm}\right)$.

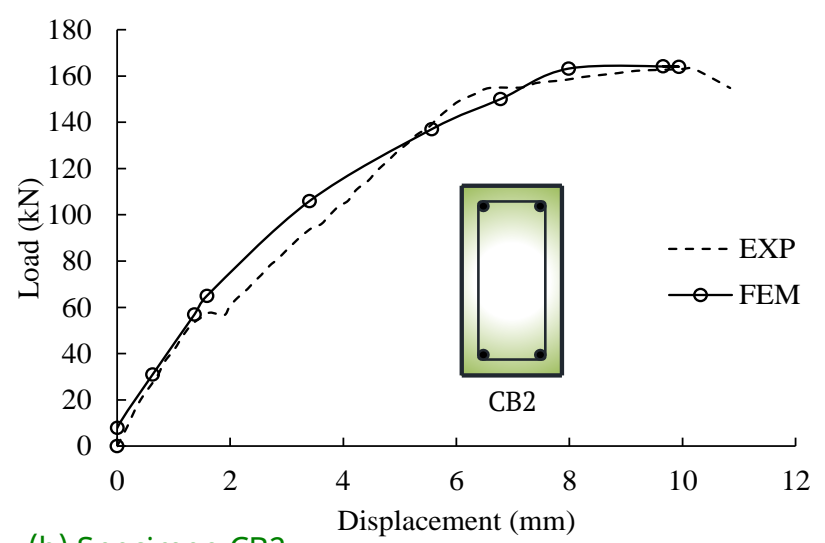

(b) Specimen CB2

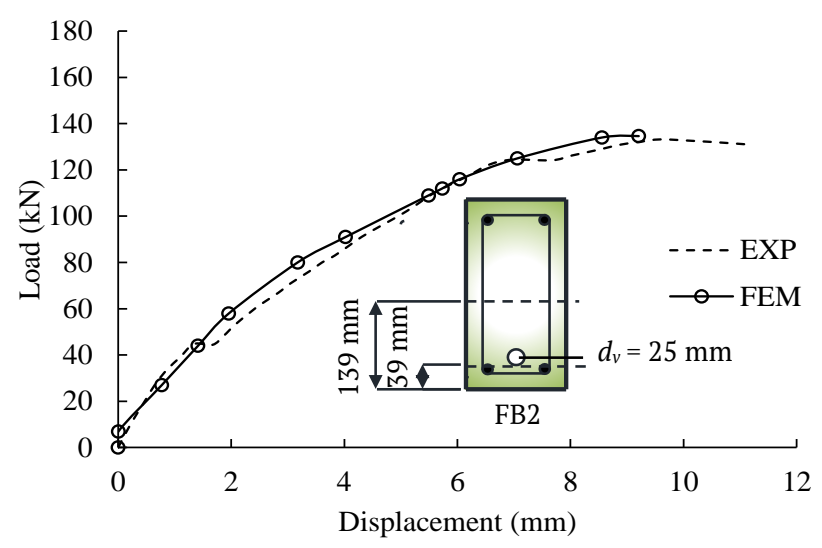

(d) Specimen FB2

Figure 5. Comparison of the modelled and experimental load-displacement responses 


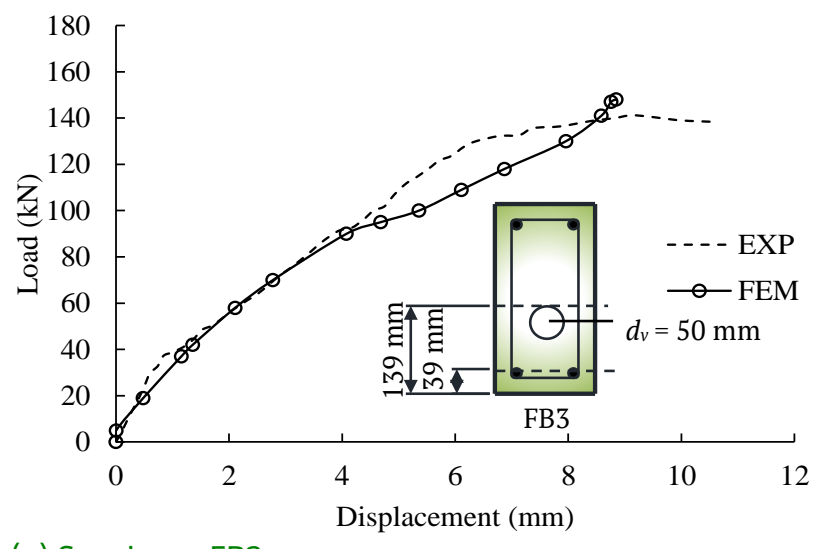

(e) Specimen FB3

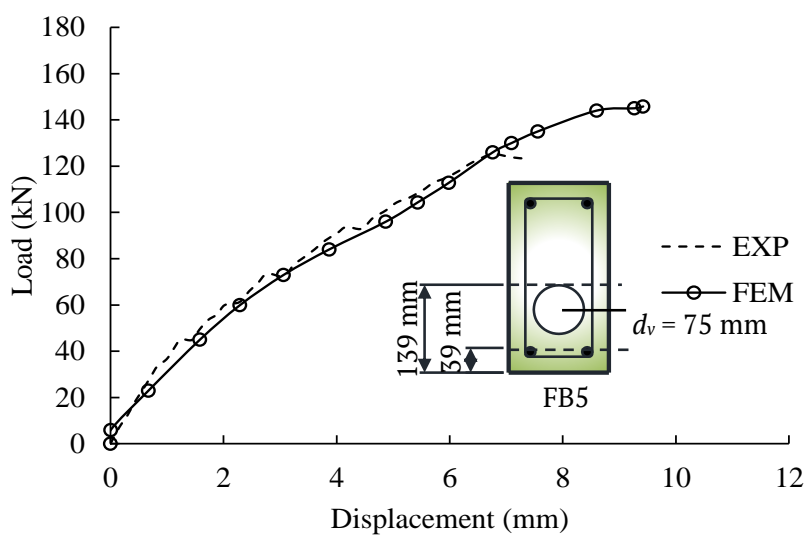

(g) Specimen FB5

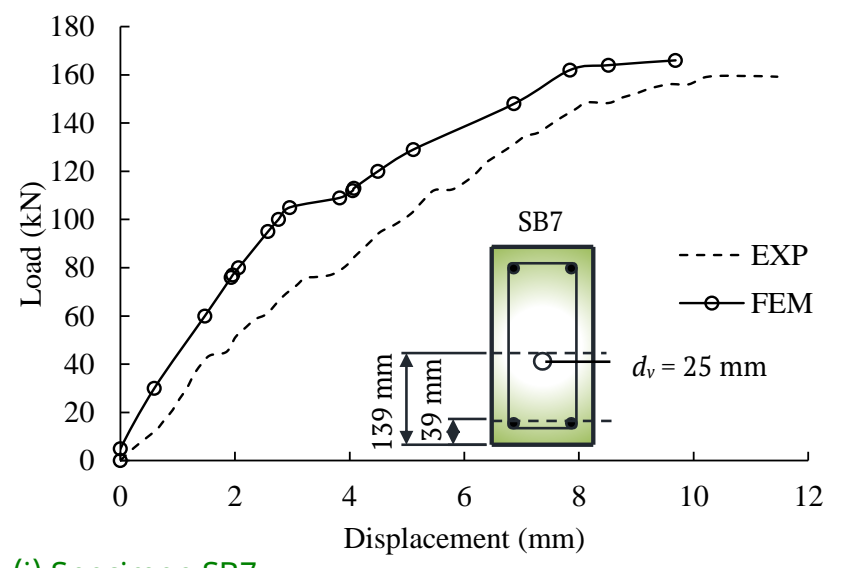

(i) Specimen SB7

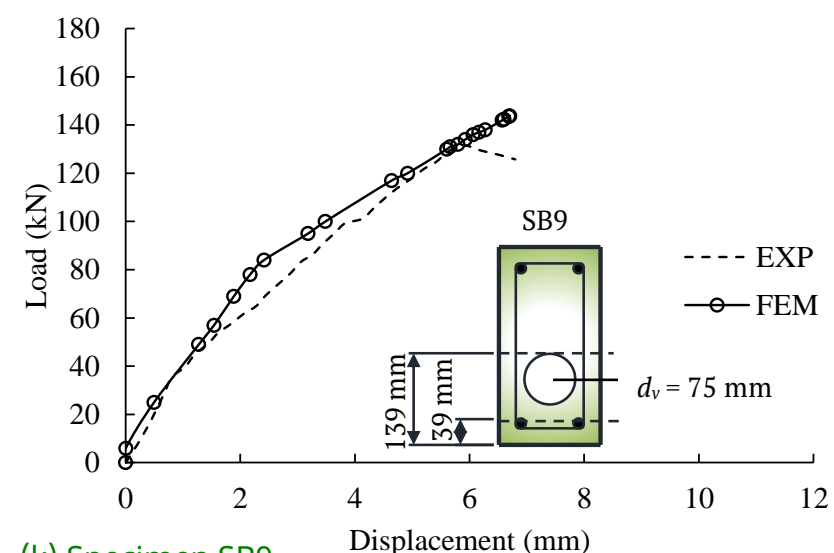

(k) Specimen SB9

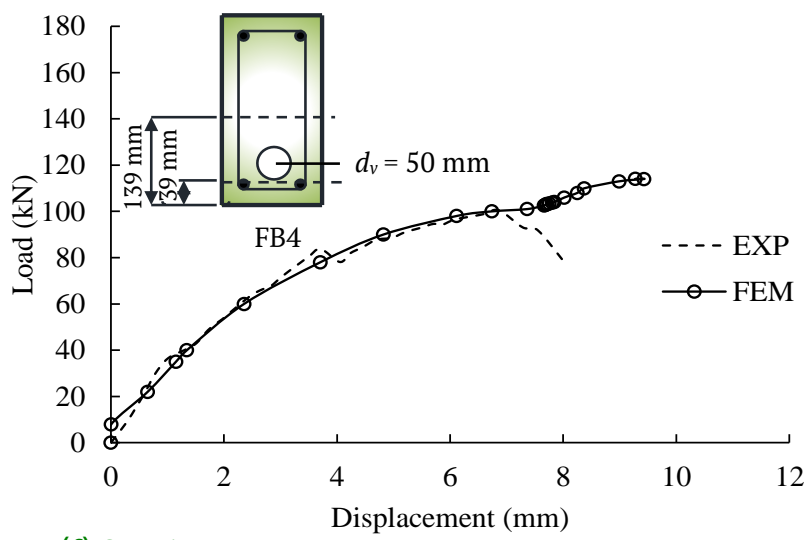

(f) Specimen FB4

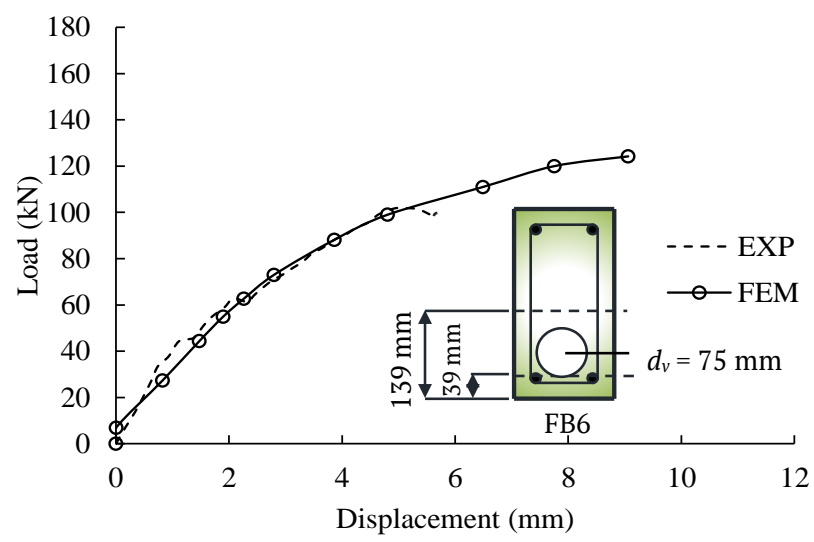

(h) Specimen FB6

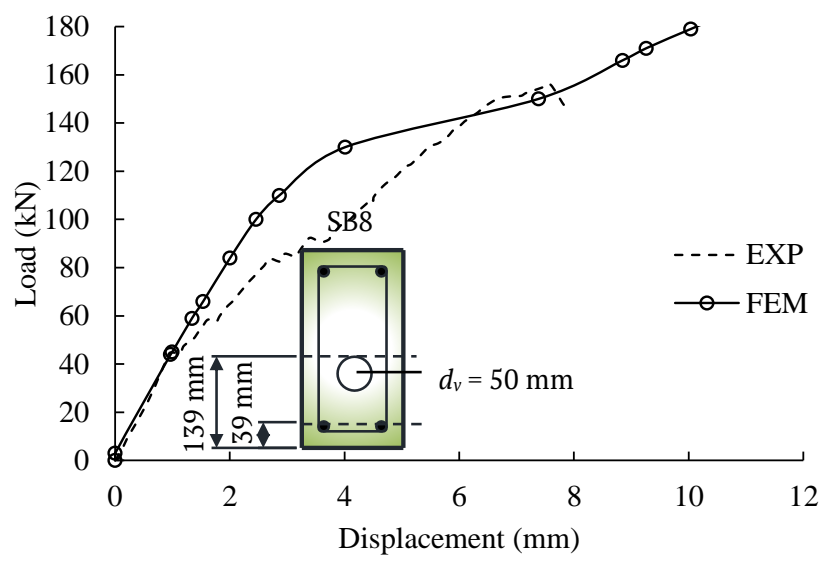

(j) Specimen SB8

Figure 5. Comparison of the modelled and experimental load-displacement responses (Cont.) 


\subsection{Mechanical Properties}

The mechanical properties of the specimens were computed from the $P-\delta$ curves, as demonstrated in Figure 6. The ultimate load capacity of the beam, $P_{u}$, was observed to be the highest point of the curve and corresponded with the ultimate deflection, $\delta_{u}$, of the beam at the $x$-axis.

The secant stiffness and the yield point were determined based on the method used by Park (1988) and Noushini et al. (2014). This involved drawing two horizontal lines at points $P_{u}$ as well as $0.75 P_{u}$ that intercepted the $P-\delta$ curve at Point A. Moreover, the gradient of the line connecting Origin $\mathrm{O}$ and Point $\mathrm{A}$ resembled the secant stiffness, $E$, of the beam and was discovered to have intercepted with line $P_{u}$ at Point B as shown in Figure 6. The Point $\mathrm{C}$ below Point $\mathrm{B}$ on the $P-\delta$ curve was found to be the yield point.

The comparison between the predicted mechanical properties of the beams and those from the experiment are presented in Table 4.
Moreover, a reliability ratio, $R_{r}$, was computed by to determine the variations in the results and the predicted results were considered reliable when (a) the variation was within $\pm 10 \%\left(0.9 \leqslant R_{r} \leqslant 1.1\right)$, and (b) a majority of the specimens ( $\geqslant 80 \%)$ met the criteria. The model was found to be unable to reliably predict the mechanical properties of the beam, as (a) none of the properties fulfilled the requirement of at least $80 \%$ satisfactory prediction, and (b) only 2 including CB2 and FB2 out of 11 specimens managed to predict all six mechanical properties with an acceptable accuracy of $\pm 10 \%$ variation from the experimental results as shown in Table 4.

The strength properties of the beams including the yield strength, $P_{y}$, and ultimate strength, $P_{u}$, were, however, predicted at a higher degree of reliabilities at $73 \%$ and $64 \%$, compared to others related to deflection such as secant stiffness, $E$, deflections, $\delta_{y}$ and $\delta_{u}$, and ductility, $\Delta$ with $55 \%$, $36 \%$, and $55 \%$, respectively.

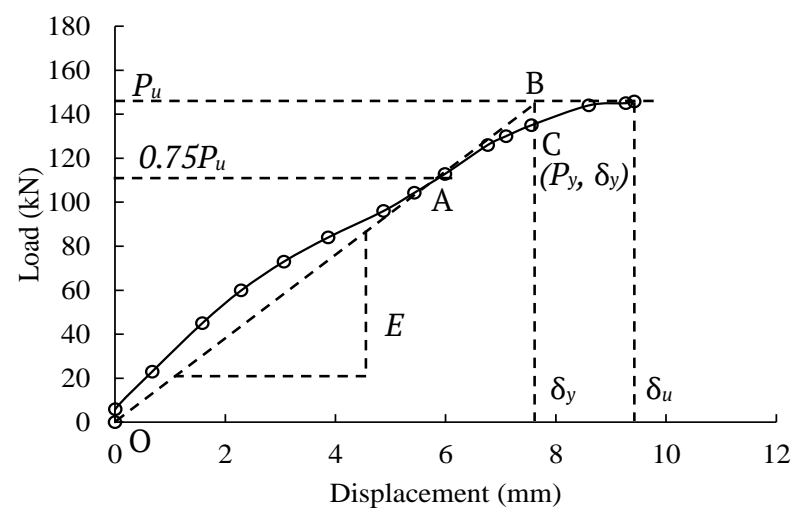

(a) FEM model

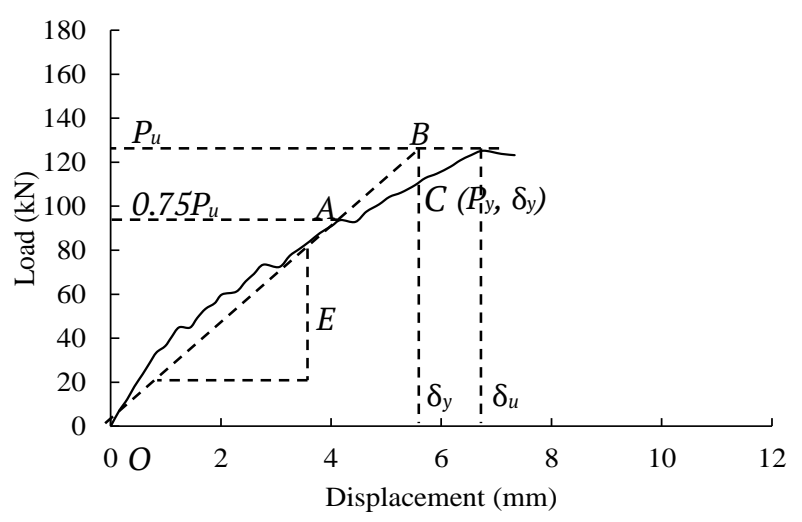

(b) Experimental test

Figure 6. Computation of mechanical properties from the load-displacement curves of specimen FB5 
Table 4. Comparison of the predicted mechanical properties (FEM) with the experimental results (EXP)

\begin{tabular}{|c|c|c|c|c|c|c|c|c|c|c|c|c|}
\hline \multirow{2}{*}{ Specimens } & \multicolumn{4}{|c|}{ Secant stiffness, $E(\mathrm{kN} / \mathrm{mm})$} & \multicolumn{4}{|c|}{ Yield strength, $P_{y}(\mathrm{kN})$} & \multicolumn{4}{|c|}{ Yield deflection, $\delta_{y}(\mathrm{~mm})$} \\
\hline & FEM & EXP & $R_{r}$ & State & FEM & EXP & $R_{r}$ & State & FEM & EXP & $R_{r}$ & State \\
\hline CB1 & 19.7 & 23.3 & 0.85 & NA & 152.5 & 140.0 & 1.09 & $\mathrm{~A}$ & 8.59 & 6.73 & 1.28 & NA \\
\hline CB2 & 26.8 & 25.8 & 1.04 & A & 143.0 & 152.2 & 0.94 & A & 6.13 & 6.32 & 0.97 & A \\
\hline FB1 & 21.3 & 17.3 & 1.23 & NA & 92.2 & 97.7 & 0.94 & A & 4.92 & 6.06 & 0.81 & NA \\
\hline FB2 & 20.9 & 20.2 & 1.03 & A & 119.5 & 122.4 & 0.98 & A & 6.44 & 6.59 & 0.98 & A \\
\hline FB3 & 17.7 & 21.7 & 0.82 & NA & 137.0 & 130.8 & 1.05 & A & 8.36 & 6.51 & 1.28 & NA \\
\hline FB4 & 19.4 & 23.4 & 0.83 & NA & 96.5 & 82.5 & 1.17 & NA & 5.88 & 4.29 & 1.37 & NA \\
\hline FB5 & 19.0 & 21.0 & 0.90 & A & 136.0 & 115.3 & 1.18 & NA & 7.67 & 5.96 & 1.29 & NA \\
\hline FB6 & 21.7 & 24.2 & 0.90 & A & 105.5 & 92.7 & 1.14 & NA & 5.72 & 4.21 & 1.36 & NA \\
\hline SB7 & 25.9 & 19.2 & 1.35 & NA & 143.1 & 148.4 & 0.96 & A & 6.41 & 8.31 & 0.77 & NA \\
\hline SB8 & 26.4 & 24.1 & 1.10 & A & 147.3 & 147.1 & 1.00 & A & 6.92 & 6.47 & 1.07 & A \\
\hline SB9 & 26.8 & 25.9 & 1.03 & A & 126.6 & 119.7 & 1.06 & A & 5.37 & 5.09 & 1.06 & A \\
\hline Reliability & & & & $55 \%$ & & & & $73 \%$ & & & & $36 \%$ \\
\hline \multirow{2}{*}{ Specimens } & \multicolumn{4}{|c|}{ Ultimate strength, $P_{u}(\mathrm{kN})$} & \multicolumn{4}{|c|}{ Total deflection, $\delta_{u}(\mathrm{~mm})$} & \multicolumn{4}{|c|}{ Ductility, $\Delta$} \\
\hline & FEM & EXP & $R_{r}$ & State & FEM & EXP & $R_{r}$ & State & FEM & EXP & $R_{r}$ & State \\
\hline CB1 & 169.3 & 156.8 & 1.08 & $\mathrm{~A}$ & 8.98 & 10.42 & 0.86 & NA & 1.05 & 1.55 & 0.68 & NA \\
\hline CB2 & 164.2 & 163.1 & 1.01 & A & 9.66 & 10.20 & 0.95 & A & 1.58 & 1.61 & 0.98 & A \\
\hline FB1 & 104.8 & 104.8 & 1.00 & A & 8.10 & 9.73 & 0.83 & NA & 1.65 & 1.61 & 1.02 & A \\
\hline FB2 & 134.6 & 133.1 & 1.01 & A & 9.21 & 9.59 & 0.96 & $\mathrm{~A}$ & 1.43 & 1.46 & 0.98 & A \\
\hline FB3 & 148.0 & 141.2 & 1.05 & $\mathrm{~A}$ & 8.85 & 9.11 & 0.97 & $\mathrm{~A}$ & 1.06 & 1.40 & 0.76 & NA \\
\hline FB4 & 114.1 & 100.4 & 1.14 & NA & 9.28 & 6.87 & 1.35 & NA & 1.58 & 1.60 & 0.99 & $\mathrm{~A}$ \\
\hline FB5 & 145.8 & 125.2 & 1.16 & NA & 9.42 & 6.76 & 1.39 & NA & 1.23 & 1.13 & 1.09 & A \\
\hline FB6 & 124.2 & 101.8 & 1.22 & NA & 9.06 & 5.07 & 1.79 & NA & 1.58 & 1.20 & 1.32 & NA \\
\hline SB7 & 166.0 & 159.6 & 1.04 & A & 9.69 & 10.48 & 0.92 & A & 1.51 & 1.26 & 1.2 & NA \\
\hline SB8 & 182.7 & 156.0 & 1.17 & NA & 10.62 & 7.59 & 1.40 & NA & 1.53 & 1.17 & 1.31 & NA \\
\hline SB9 & 143.8 & 131.7 & 1.09 & $\mathrm{~A}$ & 6.71 & 5.88 & 1.14 & NA & 1.25 & 1.16 & 1.08 & $\mathrm{~A}$ \\
\hline Reliability & & & & $64 \%$ & & & & $36 \%$ & & & & $55 \%$ \\
\hline
\end{tabular}

\subsection{Parametric Response}

The parametric responses of the beams were observed from three specimen groups:

a. Group 1: Hollow beams with the void at the neutral axis and subjected to flexural load.

b. Group 2: Hollow beams with the void near the soffit and subjected to flexural load.

c. Group 3: Hollow beams with the void at the neutral axis and subjected to a shear load.

The similarities and dissimilarities from the modelled and experimental results are highlighted in Figure 7 in reference to Table 4. Both the modelled and the experimental results agreed that: a. The longitudinal void in the hollow beam affected the yield and the ultimate strengths of the beam under flexural load due to the fact that none of the specimens performed better than the solid beam.

b. A small void is not always beneficial to the hollow beam due to the effect it has on its strength when placed at the neutral axis.

c. A large void was found to be detrimental to the shear resistance as observed from the poor performance of the hollow beam under shear load.

d. The void was more effective at the neutral axis than closer to the soffit as observed with the 
Specimens in group 1 outperforming those in group 2.

However, the modelled and experimental results contradicted each other in terms of:

a. The effects of the longitudinal void on the shear strength of the hollow beam: The model predicted SB8 to be the strongest among the specimen group while it was CB2 in the experiment.

b. The effects of the incremental void size on the beam strength at the neutral axis: The model predicted a mild drop of $-1.5 \%$ in the ultimate strength due to the increase in void size from $50 \mathrm{~mm}$ to $75 \mathrm{~mm}$ in specimens FB3 and FB5 while a significant drop of $-11.3 \%$ was recorded in the experiment.

c. The parametric responses of the hollow beams in terms of the stiffness, displacement, and ductility of the beam: The model predicted an increase in the ultimate deflection of the beam in specimen group 1 as the void diameter increased but a different result was presented in the experiment.

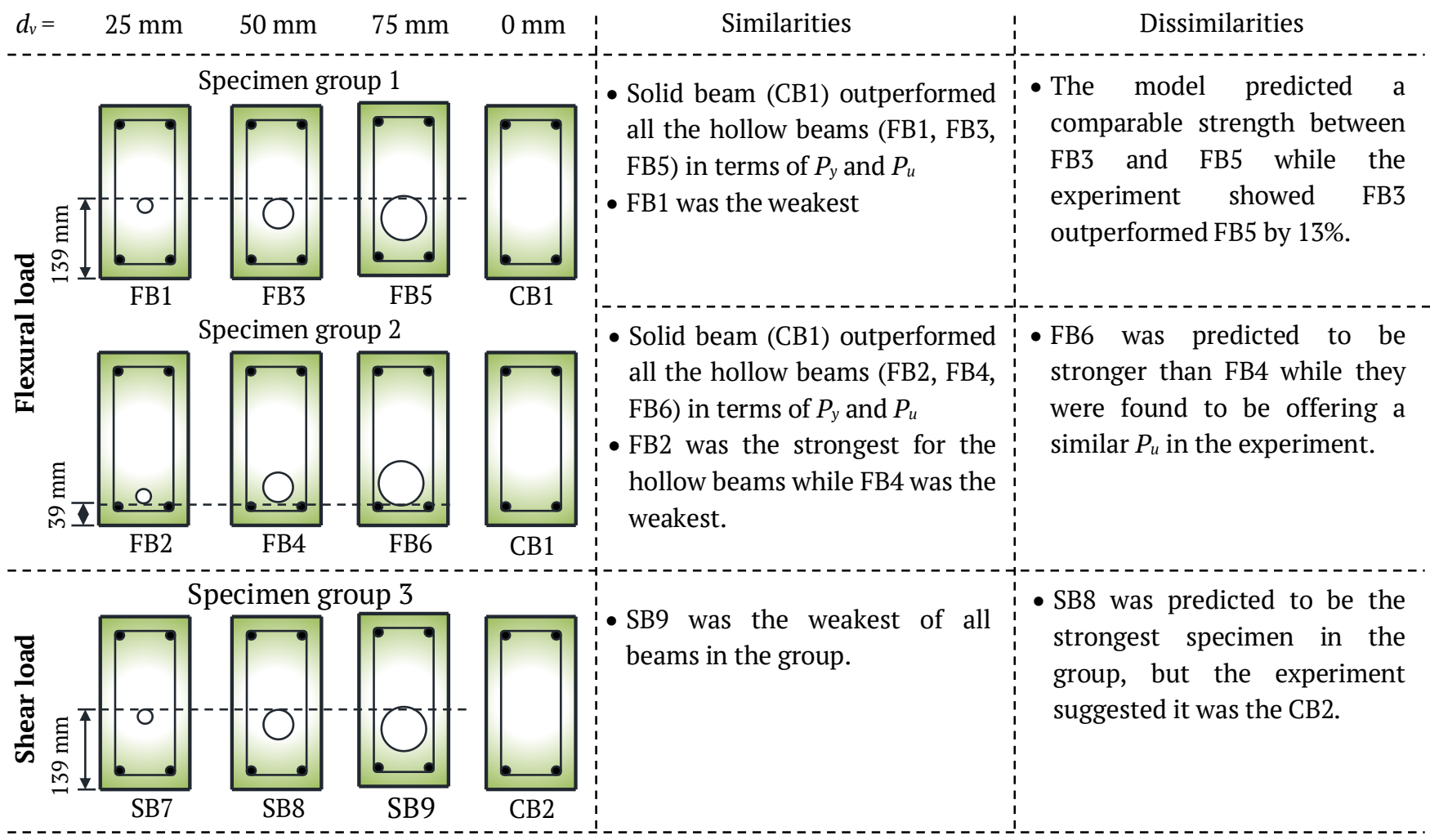

Figure 7. Similarity and dissimilarity of the parametric response between the modelled and experimental results 


\subsection{Limitations}

The inaccurate prediction of the beam deflection by the model was found to be the main cause of its nonreliability. This subsequently affected the reliability in predicting the stiffness, ductility, and probably, the strength of the beam. The variations observed were also found to be due to the compound effects of inappropriate assumptions of:

a. The properties of the materials: The actual properties of the concrete, steel bars, and shear links need to be tested in the laboratory and adopted in the model.

b. The beam support condition: The model assumed the beam to be supported by two frictionless rollers while rocker supports were used in the experiment. The contact surface between the beam and the rocker supports was not also treated to be completely free from friction.

c. The bonding conditions between the concrete and reinforcement bars: The model assumed a linear bond while the experiment made use of interlocking.

d. Composite reactions of the materials: The model ignored the PVC pipe used to create the longitudinal void in the beam when it should have been theoretically designed to offer some strength to the beam with further effects on the deflection.

e. The meshing shape and size of the model need to be further refined.

In addition, the model did not accommodate nor define the failure criteria or strain limit of the concrete and the crack propagation. Therefore, the crack pattern and failure mode of the beam were not modelled nor validated. There were a good agreement between the modelled and experimental results at the initial stage of the test, particularly at loads lower than $40 \mathrm{kN}$ but the first crack was recorded in the experiment after this value (Ngu, 2017). Therefore, the modelled results were considered more reliable if the crack propagation was considered but since that was not the case, the accuracy of the predicted beam deflection was affected and this subsequently led to the unreliable prediction of other mechanical properties.

\section{CONCLUSION}

A reliability analysis of the finite element model developed with the aid of a computer program, Ansys, was conducted in this paper to predict the response of reinforced concrete hollow beams in terms of (a) load-displacement, (b) mechanical properties, and (c) parametric responses of the hollow beams.

Despite some similarities observed from the modelled and the experimental results, the reliability of the model was questionable as observed from the poor prediction of the beam deflection which later led to significant variations of relevant mechanical properties including stiffness, deflection, and ductility.

Some parametric responses related to the strength properties of the beam such as the yield and ultimate strengths were, however, in-line with the experimental results. For example, they both agreed the longitudinal void with a diameter of $1 / 3$ times the beam width should be placed at the neutral axis to produce an effective hollow beam.

There is, therefore, the need to use caution in the application of simulated results industrially or for further research studies. This should involve (a) strategically cross-checking the predicted results with the actual responses, (b) conservatively applying some factors of safety to increase the confidence level, and (c) selectively adopting the results proven with a higher degree of reliability.

To improve the reliability, the model should be revised in terms of (a) the material properties, (b) boundary conditions of the beam supports, (c) bonding conditions between different materials, and (d) meshing shape and size used in the model. Specifically, the materials and bonding properties 
used in the model also need to be calibrated with the experimental results. Moreover, the PVC pipe used to create the void should be simulated in the model.

\section{DISCLAIMER}

The authors do not have any commercial or associative interest with the ability to cause a conflict of interest in this research.

\section{ACKNOWLEDGEMENTS}

This research was supported by the Research Grants of University College of Technology Sarawak, UCTS/RESEARCH/2/2018/02.

\section{REFERENCES}

Al-Gasham, T. S. S., 2015. Reinforced Concrete Moderate Deep Beams with Embedded PVC Pipes. Wasit Journal of Engineering Science, 3(1), pp. 1928.

Alnuaimi, A. S., Al-Jabri, K. S. \& Hago, A., 2008. Comparison between solid and hollow reinforced concrete beams. Materials and Structures, 41(2), pp. 269-286.

Bhattarai, B. P. \& Bhattarai, N., 2017. Experimental Study on Flexural Behavior of Reinforced Solid and Hollow Concrete Beams. International Journal of Engineering Research and Advanced Technology (IJERAT), 3(11), pp. 1-8.

Dhinesh, N. P. \& Satheesh, V. S., 2017. Flexural Behaviour of Hollow Square Beam. International Journal of Scientific Engineering and Applied Science (IJSEAS), 3(3), pp. 236-242.

Hussain Alshimmeri A. J. \& Ghadhban Al-Maliki, H. N., 2014. Structural Behavior of Reinforced Concrete Hollow Beams under Partial Uniformly Distributed Load. Journal of Engineering, 20(7), pp. 130-145.

Inoue, S. \& Egawa, N., 1996. Flexural and Shear Behaviour of reinforced concrete hollow beams under reversed cyclic loads. Eleventh World Conference on Earthquake Engineering.

Joy, J. \& Rajeev, R., 2014. Effect of Reinforced Concrete Beam with Hollow Neutral Axis IJSRD International Journal for Scientific Research \& Development, 2(10), pp. 341-348.

Kumbhar, U. N. \& Jadhav, H. S., 2018. Flexural Behaviour of Reinforced Concrete Hollow Beam with Polypropylene Plastic Sheet Infill. International Research Journal of Engineering and Technology (IRJET), 5(5), pp. 1517.

Manikandan, S., Dharmar, S. \& Robertravi, S., 2015. Experimental Study on Flexural Behaviour of Reinforced Concrete Hollow Core Sandwich Beam. International Journal of Advance Research in Science and Engineering, 4(1), pp. 937-946.

Mathew, I. \& Varghese, S. M., 2016. Experimental Study on Partial Replacement of Concrete in and Below Neutral Axis of Beam. International Journal of Innovative Research in Technology, 3(4), pp. 188192.

Ngu, J. T. S., 2017. The Behaviour of Reinforced Concrete Hollow Beam under Incremental Flexural and Shear Load. Final Year Project Report, School of Engineering and Technology, University College of Technology Sarawak.

Noushini, A., Samali, B. \& Vessalas, K., 2014. Performance of Concrete Beam Elements Reinforced with Polyvinyl Alcohol (PVA) Micro Fibres. Concrete in Australia, 40, pp. 22-27.

Park, R., 1988. Ductility Evaluation from Laboratory and Analytical Testing. The 9th World Conference on Earthquake Engineering, TokyoKyoto, Japan, pp. 605-616.

Parthiban, N. \& Neelamegam, M., 2017. Flexural Behavior of Reinforced Concrete Beam with Hollow Core in Shear Section. International Research Journal of Engineering and Technology (IRJET), 4(4), pp. 2263-2274. 
Ragavi, L., 2017. Behaviour of Reinforced Concrete Hollow Beams under Monotonic Loading. World Journal of Technology, Engineering and Research, 2(1), pp.127-136.

Sariman, S. \& Nurdin, A. R., 2018. Flexural Behavior of T Shaped Reinforced Concrete Hollow Beam With Plastic Bottle Waste. International Journal of Civil Engineering and Technology (IJCIET), 9(4), pp. 534-543.
Varghese, A. \& Joseph, B. M., 2016. Experimental and Numerical Studies on Reinforced Concrete Hollowcore Sandwich Beams. International Journal of Innovative Research in Science, Engineering and Technology, 5(8), pp. 1473014737.

Varghese, N. \& Joy, A., 2016. Flexural Behaviour of Reinforced Concrete Beam with Hollow Core at Various Depth. International Journal of Science and Research (IJSR), 5(5), pp. 741-75 